OPEN ACCESS

Edited by:

Wei Bao,

The University of lowa, United States

Reviewed by:

Saul Oswaldo Lugo Reyes, National Institute of Pediatrics, Mexico

Federico Biscetti,

Catholic University of the Sacred

Heart, Italy

*Correspondence:

Ardeshir Abbasi

Ardeshir.abbasi66@gmail.com

Specialty section: This article was submitted to

Clinical Diabetes,

a section of the journal

Frontiers in Endocrinology

Received: 29 June 2020 Accepted: 19 January 2021

Published: 04 March 2021

Citation:

Rahmani-Kukia N and Abbasi A (2021) Physiological and Immunological Causes of the Susceptibility of Chronic Inflammatory Patients to COVID-19 Infection: Focus on Diabetes.

Front. Endocrinol. 12:576412. doi: 10.3389/fendo.2021.576412

\section{Physiological and Immunological Causes of the Susceptibility of Chronic Inflammatory Patients to COVID-19 Infection: Focus on Diabetes}

\author{
Nasim Rahmani-Kukia ${ }^{1}$ and Ardeshir Abbasi ${ }^{2 *}$ \\ ${ }^{1}$ Department of Biochemistry, School of Medicine, Shiraz University of Medical Sciences, Shiraz, Iran, ${ }^{2}$ Department of \\ Immunology, Faculty of Medical Sciences, Tarbiat Modares University, Tehran, Iran
}

The coronavirus disease 2019 (COVID-19) pandemic has recently emerged, which was then spread rapidly in more than 190 countries worldwide so far. According to the World Health Organization, 3,232,062 global cases of COVID-19 were confirmed on April 30 ${ }^{\text {th }}$ with a mortality rate of $3.4 \%$. Notably, the symptoms are almost similar to those of flu such as fever, cough, and fatigue. Unfortunately, the global rates of morbidity and mortality caused by this disease are more and still increasing on a daily basis. The rates for patients suffering from inflammatory diseases like diabetes, is even further, due to their susceptibility to the pathogenesis of COVID-19. In this review, we attempted to focus on diabetes to clarify the physiological and immunological characteristics of diabetics before and after the infection with COVID-19. We hope these conceptions could provide a better understanding of the mechanisms involved in COVID-19 susceptibility and increase the awareness of risk to motivate behavior changes in vulnerable people for enhancing the prevention. Up to now, the important role of immune responses, especially the innate ones, in the development of the worst signs in COVID-19 infection have been confirmed. Therefore, to better control patients with COVID-19, it is recommended to consider a history of chronic inflammatory diseases as well as the way of controlling immune response in these patients.

Keywords: COVID-19, diabetes, ACE2, chronic inflammatory disease, immune responses

\section{INTRODUCTION AND EPIDEMIOLOGY OF COVID-19}

In December 2019, an unknown pneumonia was identified in Wuhan, China. In past years, two pneumonia-related to coronaviruses have been appeared with the name of severe acute respiratory syndrome coronavirus (SARS-CoV) in 2002 and as Middle East respiratory syndrome coronavirus (MERS-CoV) in 2012, which infected nearly 8,422 and 1,600 people and resulted in 916 and 574 individuals' death, respectively $(1,2)$. Chinese scientists identified new coronavirus on January $7^{\text {th }}$ as 
SARS-CoV-2 (3). Afterward, the World Health Organization (WHO) in February 2020 named it coronavirus disease 2019 (COVID-19) (4). The clinical spectrum of SARS-CoV-2 is similar to SARS, which includes systemic infection, respiratory tract involvement, and pneumonia associated with respiratory failure and eventually death (5). Moreover, the most important symptoms of this infection are fever, cough, and fatigue. COVID-19 has been rapidly spread in more than 200 countries worldwide and the rates of its morbidity and mortality are globally increasing on a daily basis. In this regard, WHO has reported 3,232,062 cases of COVID-19 up to April $30^{\text {th }} 2020$ and confirmed 3.4\% mortality rate worldwide. These mortality rates vary due to geographical location, age, and other factors in different countries (6). The comorbidity of chronic diseases such as hypertension, diabetes, and cardiovascular and respiratory diseases can increase the risk of severity and mortality in a way that these susceptibilities can be associated with the pathogenesis of COVID-19 infection. Notably, chronic diseases have several common features such as inflammatory state, immune response complications, and a higher susceptibility to infectious diseases. In a systematic study performed in February 25, 2020 on 46,248 patients, the average age to be affected by COVID-19 was shown 48 years old with the clinical symptoms of cough (86-97\%), fever (59-76\%), fatigue (34-68\%), and shortness of breath (21-40\%). Moreover, in terms of comorbidity, the prevalence rates for severe COVID-19 were as follows: hypertension (22-24\%), diabetes (6-11\%), cardiovascular disease (4-7\%), and respiratory system diseases (1-3\%), which are higher compared to non-severe patients (7). In another study conducted on 1,527 COVID-19 patients with chronic diseases, the comorbid conditions were hypertension (17.1\%), cardiovascular disease (16.4\%), and diabetes (9.7\%) (8). In addition, on 637 MERS-CoV patients, a $50 \%$ prevalence rate for both diabetes and hypertension was verified (9). Out of 41 cases of COVID-19 in Wuhan-China, $20 \%$ of patients had diabetes comorbidity (10). Therefore, comorbidity of diabetes mellitus is one of the most common COVID-19-related death responsiveness. Since understanding the causes of high susceptibility to COVID-19 can guide the vulnerable population to evaluate the infection risk and sever outcomes, the aim of this study is to review the role of diabetes in facilitating the improvement of COVID-19.

\section{DIABETES AND COVID-19}

Diabetes as a complex metabolic and maybe an inflammatory disorder is characterized by hyperglycemia. If hyperglycemia prolongs for a long time, pro-inflammatory responses can be triggered, especially in macrophages. This can enhance the risk of diabetes-associated complications (such as cardiovascular and heart diseases), and being infected and seriously ill from infections (11). Diabetes is pathologically classified into type 1 (T1D) and type 2 (T2D). However, regardless of the type of diabetes, the severity of illness differs according to the age, complications, and how well it is controlled. It has been documented that old aged patients with pre-existing comorbidities (obesity, hypertension, heart disease, etc.), uncontrolled diabetes, and high inflammatory factors are more disposed to severe illness from COVID-19 and even display a high mortality rate from it (12). However, the interaction between diabetes and COVID-19 is reciprocal. As people with diabetes are more susceptible to COVID-19, infection with SARS-CoV-2 also can exacerbate the dysglycemia, inflammatory responses, and diabetic complications such as diabetic ketoacidosis (13) and hypokalemia, which increase the risk of being critically ill (14).

On the other hand, obesity as a general comorbidity with diabetes, improves the systemic chronic inflammation by affecting the both innate and adaptive immune systems as well as the level of IL- 6 and even TNF- $\alpha$ (15). It has been indicated that both diabetes and obesity can prompt the cytokine storm (16) and also impair the coagulation system and thrombotic mechanisms (17), which are also identified in COVID-19 (18). Therefore, infection with SARS-CoV-2 in these patients can exacerbate the pre-existent pro-inflammatory condition, which in turn can improve the cytokine storm as well as several organ dysfunctions. Therefore, the following guidelines (Table 1) are recommended to be considered in patients:

TABLE 1 | Regarding for Diabetics and people with chronic diseases before and during comorbidity with COVID-19.

\begin{tabular}{|c|c|c|}
\hline Subject & Description Subject & Reference \\
\hline Hyperglycemia & $\begin{array}{l}\text { Hyperglycemia can increase the risk of severe outcomes resulting from COVID-19, the length of hospitalization, and even the risk of } \\
\text { death, which can be reduced by glycemic control. }\end{array}$ & $(19,20)$ \\
\hline Nutrition & $\begin{array}{l}\text { Due to the same nutrition of comorbidity diabetic patients with COVID-19 and other COVID-19 patients, careful attention should be paid } \\
\text { to nutrition, minerals, proteins, and vitamins in these patients. }\end{array}$ & $(21)$ \\
\hline Exercise & $\begin{array}{l}\text { Lack of exercise can reduce the immune response of these patients; therefore, a proper indoor exercise is needed to regulate and } \\
\text { strengthen the immune system in the patients affected by COVID-19. }\end{array}$ & (22) \\
\hline Vaccination & $\begin{array}{l}\text { Because of similarities in the functional mechanism of both flu and COVID-19 infections, vaccination may reduce the risk of COVID- } 19 \text {. } \\
\text { This suggestion is supported by a study performed on } 91,605 \text { diabetics after the flu vaccination, and reported a reduction in the } \\
\text { prevalence rate of pneumonia by } 55 \% \text { in patients over the age of } 65 \text { years old and by } 43 \% \text { in those under the age of } 65 \text { years old. } \\
\text { COVID-19 also has some flu-like complications (such as fever, cough, and fatigue), which may be reduced to some extent by flu } \\
\text { vaccination. }\end{array}$ & $(23-25)$ \\
\hline Stress & $\begin{array}{l}\text { Stress in comorbidity diabetic patients with COVID-19 increases blood sugar level and exacerbates mortality in these patients. Therefore, } \\
\text { anxiety and stress should be controlled and also reduced. }\end{array}$ & $(26-28)$ \\
\hline $\begin{array}{l}\text { Pancreatic } \\
\text { tissue }\end{array}$ & $\begin{array}{l}\text { Pancreatic tissue is known as a potential target for viral in patients, leading to the impaired glucose metabolism. In COVID-19, damage } \\
\text { to this tissue is better to be considered. }\end{array}$ & $(29,30)$ \\
\hline
\end{tabular}




\section{ASSOCIATION BETWEEN ANGIOTENSIN- CONVERTING ENZYME 2 AND COVID-19}

Angiotensin-converting enzyme 2 (ACE2) is a membrane aminopeptidase presented on the surface of cardiovascular, kidney, intestinal, immune, and lung endothelial cells. ACE2 can degrade angiotensin II and produce angiotensin 1-7. Angiotensin 1-7 unlike angiotensin II has anti-oxidant, antifibrotic, and anti-inflammatory properties as well as vasodilatory activity. Therefore, ACE2 can protect the lung from severe respiratory injuries like acute respiratory distress syndrome (ARDS) caused by COVID-19. ACE2 is also identified as a functional receptor and target for SARS-CoV and SARS-CoV-2 $(31,32)$. Correspondingly, the molecular modeling has revealed some similarities between these two coronavirus receptors (33). Thus, one way of viral infection is the pneumonia caused by the binding of virus to ACE2 on the surface of lung epithelial cells (18). Throughout SARS-CoV-2 entrance, ACE2 becomes downregulated, which consequently results in a high ACE/ ACE2 ratio contributing to the progression of pre-exciting proinflammatory responses and subsequently worsen outcomes from COVID-19 (34). Indeed, the expression of ACE2 becomes down regulated in diabetics as a consequence of the glycosylation process, which might be considered as a contributory factor for the severity of lung complications in comorbidity with SARS-CoV-2 invasion (35). Likewise, the ratio of ACE/ACE2 is found to be significantly higher in diabetics compared to healthy controls. Moreover, the relationship among ACE/ACE2 level and the increased blood pressure, fasting blood glucose, serum creatinine, and hemoglobin A1c (HbAlc) has also been demonstrated (36). As a result, it seems that there is a correlation between ACE2 level and susceptibility to COVID-19 in diabetic, which is highly debatable, so it should be considered in these patients.

\section{IMMUNE CELLS IN DIABETIC PATIENTS}

The balance among immune cells is essential for preserving homeostasis and the best performance of immune responses, however this balance can be impaired in diabetics. Several studies have revealed the increased pathological function of TCD4 cells in obesity, insulin resistance, and diabetes. TCD4 effector cells can be divided into inflammatory [T helper1 (Th1) and Th17) and anti-inflammatory (Th2 and regulatory Th (Treg)] cells with their specific cytokine secretions (37). It has been demonstrated that in adipose tissue and peripheral blood of diabetic patients, CD4 cells tend to be polarized into Th1 and Th17 inflammatory cells. However, the anti-inflammatory polarization of Th2 and its secreted cytokines (IL-4, IL-5, and IL-13) is reduced $(37,38)$. Moreover, in diabetes, it has been found that the Th1/Th2 ratio and the level of the related cytokines (IL-4, IL-10, IL-13, and IFN- $\gamma$ ) become remarkably high, whereas the anti-oxidant level decreases (39). On the other hand, it has been proved that the increased cytokine production by Th1 (IFN- $\gamma$, IL-2, TNF- $\alpha$, and
TNF- $\beta$ ) and Th17 (IL-6, IL-17A, and IL-17F) in diabetics can affect the HbAlc level (40).

Treg as a regulator of immune responses, constitutes about 5$20 \%$ of overall CD4 cells which is characterized by CD4, CD25, and Foxp3. Moreover, Treg plays a very essential role in suppressing $\mathrm{T}$ effector cells, inflammatory responses, and protecting against autoimmunity $(41,42)$. The activation of these cells leads to the secretion of IL-10, and TGF- $\beta$ as well as the expression of co-inhibitory molecule cytotoxic T lymphocyte antigen-4 (CTLA-4) on their surface in order to inactivate the T effector cells. It has been shown that Treg is decreased in diabetes (43). Furthermore, the balance between Treg and Th1 or Th17 is very important in diabetic patients. Because, the balance between Treg/Th17 and Treg/Th1 ratio decrease in patients suffering from $\mathrm{T} 2 \mathrm{D}$ (44). $\mathrm{T} \mathrm{CD} 8^{+}$is also activated against infection and by releasing IFN- $\gamma$ and TNF- $\alpha$ cytokines, which consequently increases the antiviral responses. However, an elevation in the level of $\mathrm{T} \mathrm{CD}^{+}$has been verified in diabetes (45).

Gamma delta $\mathrm{T}(\mathrm{T} \gamma \delta)$ cells also play an important role in generating chronic inflammation by secreting cytokines (like IFN- $\gamma$ and TNF- $\alpha$ ) and affecting the function of other immune cells such as macrophages, cytotoxic T lymphocytes, Th1, Th2, Treg, and Th17 cells in the diabetics (46). It has been proved that natural killer $\mathrm{t}$ (NKT) cells which produce some cytokines such as IL- 4 and IFN- $\gamma$ are decreased in diabetic patients. Reduction of NKT cells leads to increase in the level of M1 macrophages, insulin resistance, and glucose intolerance (47). In addition, the enhancement of B cells, which play key roles in the development of insulin resistance following the production of IgG, activations of macrophages and $\mathrm{T}$ cells have been demonstrated in diabetes (48). NK cells, as a type of immune cells are divided into the following two subsets based on CD56 marker: dim and bright. CD56 ${ }^{\text {dim }}$ NK cells have cytotoxic effects, while, CD56 ${ }^{\text {bright }}$ ones are more likely to produce pro-inflammatory cytokines. In chronic inflammatory diseases like diabetes, CD56 ${ }^{\text {bright }}$ NK cells are dominant which, release more inflammatory cytokines (49).

Changes in the myeloid cells such as macrophages, monocytes, neutrophils, eosinophils, and basophils happen in diabetic patients as well. It has been revealed that most macrophages in the adipose tissue of diabetics are M1 macrophages, which play key functions during the pathological processes by secreting TNF- $\alpha$ and triggering chronic inflammation in these patients (50). Additionally, the elevation of monocytes, as effective cells on the reduction of neutrophils and eosinophils numbers as well as on the development of inflammation is perceived in diabetics $(51,52)$. This imbalance in the immune system of diabetics increases their susceptibility to viral pneumonia as shown in Figure 1. An obvious proinflammatory Th1 and Th17 responses was detected in the cytokine profile of SARS patients with diabetes. Similarly a significant increase has been identified in IFN- $\gamma$ and IL-17A level in the lungs of patients infected with MERS-CoV and diabetes $(53,54)$. Therefore, it seems that any imbalance in the immune responses can increase people's susceptibility to viral infections. 


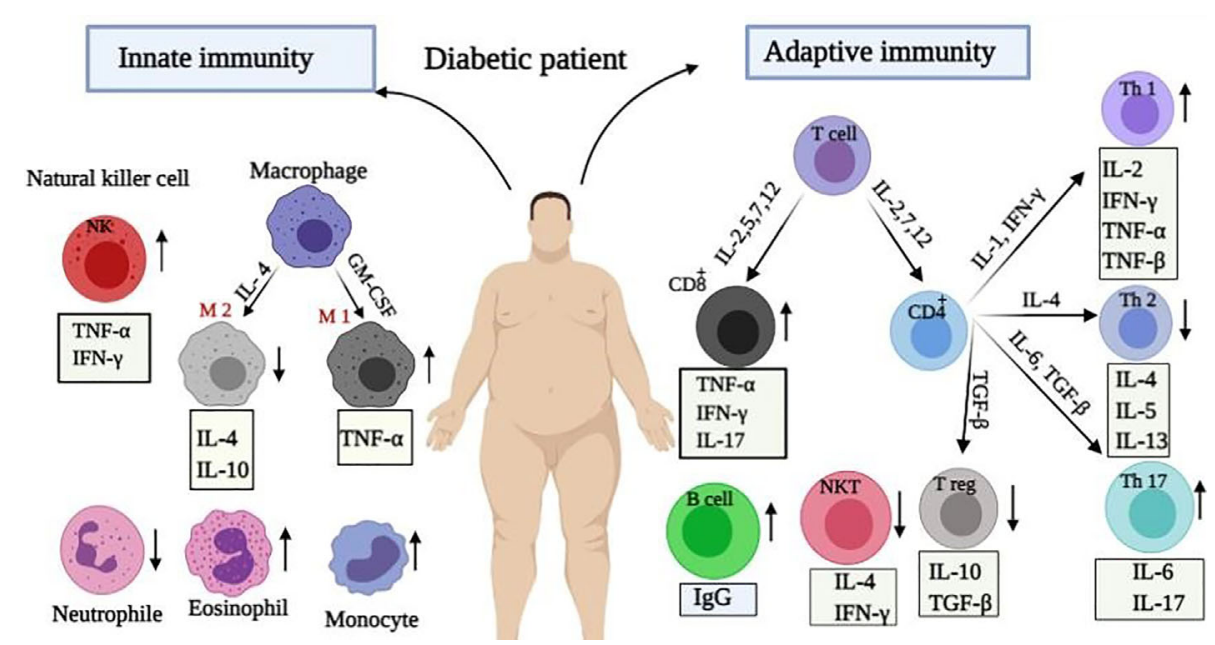

FIGURE 1 | Immunological alteration in diabetic patients. Immune responses change during diabetices. Changes in innate immunity include: increase in the plasma levels of macrophages, NK cells and eosinophils, as well as their secreted cytokines with a reduction in the number of neutrophils. Moreover, adaptive immunity changes included: enhancement in Th1, Th17, TCD8 ${ }^{+}$cells, and released cytokines whereas reduction in Th2, Treg, and NKT cells.

\section{IMMUNE RESPONSE IN COVID-19 INFECTION}

Immune responses to COVID-19 can be divided into two phases as follows: non-severe and severe. At non-sever response, immune system tries to eliminate the virus by IFN-I $(\alpha / \beta)$ and avoids the stage's progression to the severe phase. At severe response, inflammation arises in the lung, which may be due to impaired IFN-I regulation. Overproduction of IFN-I increases the penetration of neutrophils, macrophages, and inflammatory factors into the lung, which is then followed by cytokine storm syndrome, as well (Figure 2). Since chronic inflammation is generated in the body of patients with chronic diseases like diabetes, the balance of the immune system becomes disregulated and the inflammatory state potentially perseveres. In this situation, the numbers of Th1, Th17, M1 macrophage, NK cells (most in the affected area are probably CD56 ${ }^{\text {bright }}$ ) and their secreted inflammatory cytokines increase. Moreover, the negative regulation of Treg and its secreted cytokines is decreased, which result in the loss of control and homeostasis of immune responses. All of these can heighten the diabetic patients' susceptibility to severe COVID-19. On the other hand, SARS-CoV-2 invasion to lung enhances the influx of activated neutrophils and macrophages. An increase in the content of activated immune cells at the site of infection and their released inflammatory cytokines triggers cytokine storm. Subsequently, serious pathological complications induced in the patients' lung can worsen the illness from COVID-19 and even terminate the life. This phenomenon is supported by some clinical studies. Accordingly, experimental findings of a study on patients with severe COVID-19 infection in China showed an elevation in neutrophils level and reduction in lymphocytes, monocytes, eosinophils, and basophils, which are followed by a sharp increase in the pro-inflammatory cytokines profile. Besides, the B, T, NK cells, and Treg depletion have been observed in patients compared to normal cases (55). Moreover, there was an increase in the plasma levels of IL-2, IL-7, IL-10, GCSF, interferon gamma-induced protein 10 (IP-10), monocyte chemoattractant protein-1 (MCP-1), macrophage inflammatory protein 1-alpha (MIP1- $\alpha$ ), and TNF $\alpha$ in ICU patients (10). High concentrations of IL-1 $\beta$, IFN- $\gamma$, IP-10, and MCP-1 in COVID-19 patients have also been detected $(10,56)$. Notably, patients who were in the ICU had higher inflammatory factors (that can be associated with cytokine storm in severe patients) compared to other patients. These clinical findings indicated that lymphocytopenia in COVID-19 patients may be due to cytokine storm (IL-1, IL-6, and TNF- $\alpha$ ) as well as pathological effects of leukocytes and macrophages. Overall, it can be suggested that innate immune responses are extremely involved in COVID-19 infection and these points can be considered for the treatment of COVID-19 patients with co-existence of other diseases to better control the innate immune responses.

\section{THE EFFECTS OF SOME ANTIDIABETIC DRUGS ON COVID-19}

Considering the above-mentioned main points stating that the immune cells pattern changes to pro-inflammatory one with high level of IL- 1 and TNF- $\alpha$ during a long-term hyperglycemia and regarding amplified immune responses to SARS-CoV-2 invasion in the lung of COVID-19 patients, this question arises that whether antidiabetic drugs with anti-inflammatory, antifibrotic, and anti-oxidant effects can be beneficial on prevention from infection with SARS-CoV-2 and even suffering from severe consequence of COVID-19. 


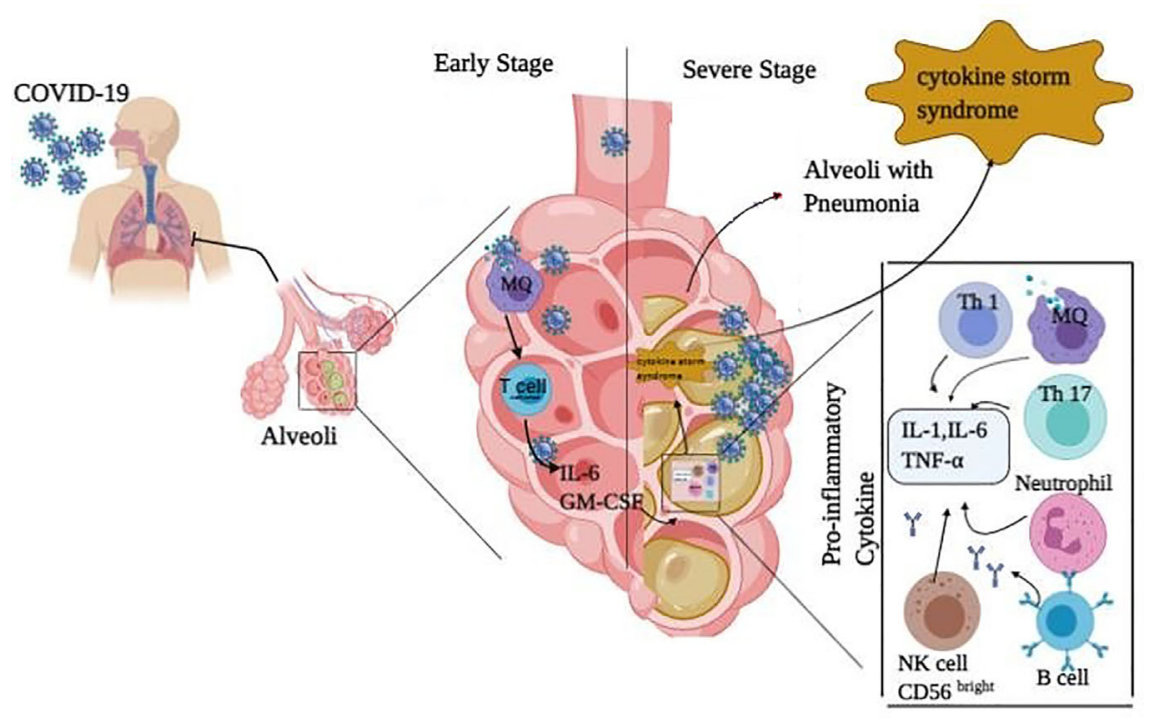

FIGURE 2 | Immune response in COVID-19 infected people. The immune responses against COVID-19 infection are divided into two phases: non-severe and severe ones. In the non-sever stage response, activated T cells and macrophages release IFN-I $(\alpha, \beta)$ to remove the virus and prevent entry to severe phase. In the severe stage of infection, inflammation occurs in the lung which may increase the penetration of neutrophils, macrophages, Th1, Th17, B cells, and NK (CD56 ${ }^{\text {bright }}$ ) cells with their secreted pro-inflammatory cytokines (IL-1, IL-6, and TNF- $\alpha$ ) into the lung. This is followed by cytokine release syndrome and pneumonia in the lung.

In this regard, several considerable theories are proposed for ACE inhibitors (ACEIs), angiotensin II Type-I receptor blockers (ARBs), and dipeptidyl peptidase 4 (DPP4) inhibitors (57). Accordingly, ACEIs and ARBs are used in patients with diabetes to prevent the risks of developing diabetes and organ failure. As a result of taking, ACE2 becomes over-expressed in these patients (58). Therefore, due to anti-inflammatory/anti-oxidant/antifibrotic and other promising effects of ACE2, it is suggested that the increased ACE2 may preserve them from sever outcomes of COVID-19 infection. However, there is a fear from their unfavorable impacts as well. Because, over-expressed ACE2 may also facilitate infection with SARS-CoV-2 (due to its receptor role), as displayed in Figure 3 (13).

On the other hand, DPP4 inhibitors, as effective hyperglycemic drugs, are frequently used in diabetes. Their biological effects is not only limited to glucose metabolism, but also the anti-inflammatory and anti-fibrotic, impacts of DPP4 inhibitors on various cells have also been proved (59). DPP4 is highly expressed on lung mesothelium and various lung cells (such as alveolar cells, resident macrophages) as well as multiple immune cell types (such as macrophages, $\mathrm{T}$ cells, $\mathrm{B} / \mathrm{NK}$, and dendritic cells) (60). Thus, it is logical to assume DPP4 effect on their functions (57). In addition, DPP4 possesses a pro-inflammatory function by stimulating monocytes to produce IL- 6 and TNF- $\alpha$. Therefore, DPP4 inhibitors can also be verified as anti-inflammatory agents (60). Accordingly, their anti-inflammatory and protective impacts have been confirmed in mice and human lung injuries (61). Moreover, it is demonstrated that DPP4 inhibitors display their positive antiinflammatory effects by reducing the high level of pro-inflammatory factors such as TNF- $\alpha$, as well as elevating anti-inflammatory IL-10 in T2D patients (Figure 3) (62). Therefore, DPP4 inhibitors exert their anti-inflammatory functions on different cell types such as macrophages, $\mathrm{T}$ cells, and lung cells. In addition, it seems that DPP4 inhibitors have some anti-fibrotic effects on the lung by affecting the proliferative and inflammatory-signaling-pathways of human pulmonary arterial smooth muscle cells and fibroblasts (63).

As a result, considering the promising inflammatory and immunological impacts of DPP4 inhibitors, they might be beneficial on modulating immune and inflammatory responses in the respiratory system of COVID-19, which are abnormally amplified to minimize the severity of illness and its mortality rate. On the other hand, it is suggested that DDP4 4 inhibitors could reduce the SARS-CoV-2 internalization/replication within the airway due to the estimated co-receptor role of DPP4 (64). In this regard, more clinical data are required to confirm these findings.

\section{CONCLUSION}

In chronic inflammatory diseases like diabetes, the proliferation, differentiation, distribution, and function of both the innate and adaptive immunities become dysregulated and the immune homeostatic balance becomes disrupted. Accordingly, these in turn make patients more susceptible to be infected with SARS$\mathrm{CoV}-2$, severe outcomes, and the increased mortality rate resulted from it compared to people without it. Since the activation of innate and adaptive immune responses plays an essential role in severity of symptoms and the risk of mortality from COVID-19, all efforts attempt to reduce the incidence and 


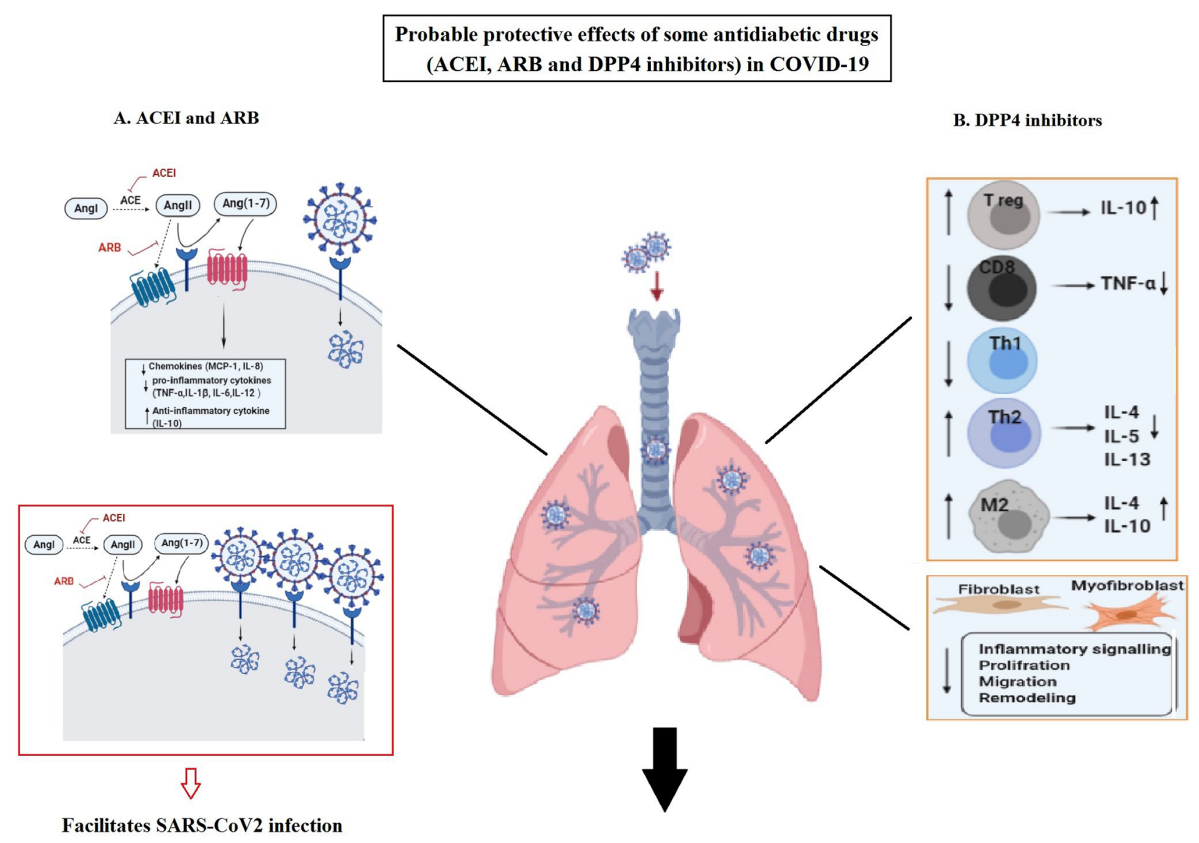

Decrease lung injury and mortality rate

FIGURE 3 | The possible protective effects of angiotensin-converting enzyme inhibitors (ACEls), angiotensin II Type-I receptor blockers (ARBs), and also dipeptidyl peptidase 4 (DPP4) inhibitors as antidiabetic drugs in COVID-19. (A) Usage of ACEls and ARB lead to over expression of ACE2. Overexpressed ACE2 can degrade angiotensin II and lead to the production of angiotensin 1-7 with favorable (anti-oxidant, anti-fibrotic, anti-inflammatory, and vasodilatory) effects in COVID-19. Its antiinflammatory function can be related to the reduction in chemokines (MCP-1 and IL-8) and pro-inflammatory cytokines (TNF- $\alpha$, IL-1 $\beta$, IL-6, and IL-12) as well as increase in anti-inflammatory cytokines (IL-10) in the lung. However, the increased ACE2 can facilitate infection with SARS-CoV-2. (B) DPP4 inhibitors exert their antiinflammatory impacts in the lung through regulating multiple immune cells function and anti-fibrotic effects by influencing fibroblasts and myofibroblasts activities. These effects may result in the decreased lung injury and mortality rate in COVID-19.

death rates. In this regard, we tried to focus on diabetes to clarify the physiological and immunological characteristics of diabetic patients once before and once after infecting with COVID-19. We hope it could provide better understanding on inflammatory mechanisms to better control the immune responses and its consequences in COVID-19.

\section{REFERENCES}

1. Badawi A, Ryoo SG. Prevalence of diabetes in the 2009 influenza A (H1N1) and the Middle East respiratory syndrome coronavirus: a systematic review and metaanalysis. J Public Health Res (2016) 5(3):130-8. doi: 10.4081/jphr.2016.733

2. Chan K, Zheng J, Mok Y, Li Y, LIU YN, Chu C, et al. SARS: prognosis, outcome and sequelae. Respirology (2003) 8:S36-40. doi: 10.1046/j.14401843.2003.00522.x

3. Phelan A, Katz R, Gostin L. The novel coronavirus originating in Wuhan. Challenges Global Health Governance JAMA (2020) 323(8):709-10. doi: 10.1001/jama.2020.1097

4. Gorbalenya AE. Severe acute respiratory syndrome-related coronavirus-The species and its viruses, a statement of the Coronavirus Study Group. BioRxiv (2020) 937862:1-16. doi: 10.1101/2020.02.07.937862v1

5. Bai Y, Yao L, Wei T, Tian F, Jin D-Y, Chen L, et al. Presumed asymptomatic carrier transmission of COVID-19. Jama (2020) 323(14):1406-07. doi: 10.1001/ jama.2020.2565

6. Guan W-j, Ni Z-y, Hu Y, Liang W-h, Ou C-q, He J-x, et al. Clinical characteristics of coronavirus disease 2019 in China. New Engl J Med (2020) 382:1708-20. doi: 10.1101/2020.02.06.20020974

\section{AUTHOR CONTRIBUTIONS}

AA: the original draft preparation, writing, editing, and graphic design. NR-K: writing, editing, and relevant idea for graphic design. All authors contributed to the article and approved the submitted version.

7. Yang J, Zheng Y, Gou X, Pu K, Chen Z, Guo Q, et al. Prevalence of comorbidities in the novel Wuhan coronavirus (COVID-19) infection: a systematic review and meta-analysis. Int J Infect Dis (2020) 30136-3:1-14. doi: 10.1016/j.ijid.2020.03.017

8. Li B, Yang J, Zhao F, Zhi L, Wang X, Liu L, et al. Prevalence and impact of cardiovascular metabolic diseases on COVID-19 in China. Clin Res Cardiol (2020) 109:1-8. doi: 10.1007/s00392-020-01626-9

9. Badawi A, Ryoo SG. Prevalence of comorbidities in the Middle East respiratory syndrome coronavirus (MERS-CoV): a systematic review and meta-analysis. Int J Infect Dis (2016) 49:129-33. doi: 10.1016/j.ijid. 2016.06.015

10. Huang C, Wang Y, Li X, Ren L, Zhao J, Hu Y, et al. Clinical features of patients infected with 2019 novel coronavirus in Wuhan, China. Lancet (2020) 395 (10223):497-506. doi: 10.1016/S0140-6736(20)30183-5

11. Peric S, Stulnig TM. Diabetes and COVID-19: Disease-ManagementPeople. Wiener Klinische Wochenschrift (2020) 1:356-61. doi: 10.1007/ s00508-020-01672-3

12. Guo W, Li M, Dong Y, Zhou H, Zhang Z, Tian C, et al. Diabetes is a risk factor for the progression and prognosis of COVID-19. Diabetes/Metabol Res Rev (2020) 36(7):e3319. doi: 10.1002/dmrr.3319 
13. Pal R, Bhadada SK. COVID-19 and diabetes mellitus: An unholy interaction of two pandemics. Diabetes Metab Syndrome: Clin Res Rev (2020) 14:513-7. doi: 10.1016/j.dsx.2020.04.049

14. Li X, Hu C, Su F, Dai J. Hypokalemia and clinical implications in patients with coronavirus disease 2019 (COVID-19). MedRxiv (2020) 20028530:1-22. doi: $10.1101 / 2020.02 .27 .20028530$

15. Coelho M, Oliveira T, Fernandes R. Biochemistry of adipose tissue: an endocrine organ. Arch Med Sci: AMS (2013) 9(2):191. doi: 10.5114/aoms.2013.33181

16. Papadokostaki E, Tentolouris N, Liberopoulos E. COVID-19 and diabetes: What does the clinician need to know? Primary Care Diabetes (2020) 14:55863. doi: 10.1016/j.pcd.2020.06.010

17. Kaye SM, Pietiläinen KH, Kotronen A, Joutsi-Korhonen L, Kaprio J, YkiJärvinen $\mathrm{H}$, et al. Obesity-related derangements of coagulation and fibrinolysis: a study of obesity-discordant monozygotic twin pairs. Obesity (2012) 20(1):88-94. doi: 10.1038/oby.2011.287

18. Magro C, Mulvey JJ, Berlin D, Nuovo G, Salvatore S, Harp J, et al. Complement associated microvascular injury and thrombosis in the pathogenesis of severe COVID-19 infection: a report of five cases. Trans Res (2020) 220:1-13. doi: 10.1016/j.trsl.2020.04.007

19. Sardu C, D’Onofrio N, Balestrieri ML, Barbieri M, Rizzo MR, Messina V, et al. Outcomes in Patients With Hyperglycemia Affected by Covid-19: Can We Do More on Glycemic Control? Diabetes Care (2020) 43:1408-15. doi: 10.2337/ figshare.12275516.v1

20. Zhou J, Tan J. Diabetes patients with COVID-19 need better blood glucose management in Wuhan, China. Metabolism (2020) 107:154216. doi: 10.1016/ j.metabol.2020.154216

21. Li T, Zhang Y, Gong C, Wang J, Liu B, Shi L, et al. Prevalence of malnutrition and analysis of related factors in elderly patients with COVID-19 in Wuhan, China. Eur J Clin Nutr (2020) 74:1-5. doi: 10.1038/s41430-020-0642-3

22. Banerjee M, Chakraborty S, Pal R. Diabetes self-management amid COVID19 pandemic. Diabetes Metab Syndrome: Clin Res Rev (2020) 14:351-4. doi: 10.1016/j.dsx.2020.04.013

23. Patel A, Jernigan DB. Initial public health response and interim clinical guidance for the 2019 novel coronavirus outbreak-United States, December 31, 2019-February 4, 2020. Morbid Mortal Weekly Rep (2020) 69(5):140. doi: 10.15585/mmwr.mm6908e1

24. Lau D, Eurich DT, Majumdar SR, Katz A, Johnson JA. Effectiveness of influenza vaccination in working-age adults with diabetes: a population-based cohort study. Thorax (2013) 68(7):658-63. doi: 10.1136/thoraxjnl-2012-203109

25. Goeijenbier M, Van Sloten TT, Slobbe L, Mathieu C, Van Genderen P, Beyer WE, et al. Benefits of flu vaccination for persons with diabetes mellitus: a review. Vaccine (2017) 35(38):5095-101. doi: 10.1016/j.vaccine.2017.07.095

26. Qiu J, Shen B, Zhao M, Wang Z, Xie B, Xu Y. A nationwide survey of psychological distress among Chinese people in the COVID-19 epidemic: implications and policy recommendations. Gen Psychiatry (2020) 33(2):1-3. doi: 10.1136/gpsych-2020-100213

27. Hartmann-Boyce J, Morris E, Goyder C, Kinton J, Perring J, Nunan D, et al. Diabetes and COVID-19: risks, management, and learnings from other national disasters. Diabetes Care (2020) 43(8):1695-703. doi: 10.2337/dc20-1192

28. Miazgowski T, Bikowska M, Ogonowski J, Taszarek A. The impact of health locus of control and anxiety on self-monitored blood glucose concentration in women with gestational diabetes mellitus. J Women's Health (2018) 27 (2):209-15. doi: 10.1089/jwh.2017.6366

29. Cure E, Cure MC. COVID-19 may affect the endocrine pancreas by activating $\mathrm{Na}+/ \mathrm{H}+$ exchanger 2 and increasing lactate levels. J Endocrinol Invest (2020) 43:1167-8. doi: 10.1007/s40618-020-01307-4

30. Wang F, Wang H, Fan J, Zhang Y, Wang H, Zhao Q. Pancreatic injury patterns in patients with COVID-19 pneumonia. Gastroenterology (2020) 159:367-70. doi: 10.1053/j.gastro.2020.03.055

31. Li F, Li W, Farzan M, Harrison SC. Structure of SARS coronavirus spike receptor-binding domain complexed with receptor. Science (2005) 309 (5742):1864-8. doi: 10.1126/science.1116480

32. Turner AJ, Hiscox JA, Hooper NM. ACE2: from vasopeptidase to SARS virus receptor. Trends Pharmacol Sci (2004) 25(6):291-4. doi: 10.1016/ j.tips.2004.04.001

33. Lu R, Zhao X, Li J, Niu P, Yang B, Wu H, et al. Genomic characterisation and epidemiology of 2019 novel coronavirus: implications for virus origins and receptor binding. Lancet (2020) 395(10224):565-74. doi: 10.1016/S0140-6736 (20)30251-8

34. Pagliaro P, Penna C. ACE/ACE2 Ratio: A Key Also in 2019 Coronavirus Disease (Covid-19)? Front Med (2020) 7:1-5. doi: 10.3389/fmed.2020.00335

35. Pal R, Bhansali A. COVID-19, diabetes mellitus and ACE2: the conundrum. Diabetes Res Clin Practice (2020) 162:1-2. doi: 10.1016/j.diabres.2020.108132

36. Mizuiri S, Hemmi H, Arita M, Ohashi Y, Tanaka Y, Miyagi M, et al. Expression of ACE and ACE2 in individuals with diabetic kidney disease and healthy controls. Am J Kidney Dis (2008) 51(4):613-23. doi: 10.1053/ j.ajkd.2007.11.022

37. Raphael I, Nalawade S, Eagar TN, Forsthuber TG. T cell subsets and their signature cytokines in autoimmune and inflammatory diseases. Cytokine (2015) 74(1):5-17. doi: 10.1016/j.cyto.2014.09.011

38. Cortez-Espinosa N, Cortés-Garcia JD, Martínez-Leija E, Rodríguez-Rivera JG, Barajas-López C, González-Amaro R, et al. CD39 expression on Treg and Th17 cells is associated with metabolic factors in patients with type 2 diabetes. Hum Immunol (2015) 76(9):622-30. doi: 10.1016/j.humimm.2015.09.007

39. Sireesh D, Dhamodharan U, Ezhilarasi K, Vijay V, Ramkumar KM. Association of NF-E2 related factor 2 (Nrf2) and inflammatory cytokines in recent onset type 2 diabetes mellitus. Sci Rep (2018) 8(1):1-10. doi: 10.1038/ s41598-018-22913-6

40. Ip B, Cilfone NA, Belkina AC, DeFuria J, Jagannathan-Bogdan M, Zhu M, et al. Th17 cytokines differentiate obesity from obesity-associated type 2 diabetes and promote TNF $\alpha$ production. Obesity (2016) 24(1):102-12. doi: 10.1002/oby. 21243

41. Dimeloe S, Burgener AV, Grählert J. Hess C. T-cell metabolism governing activation, proliferation and differentiation; a modular view. Immunology (2017) 150(1):35-44. doi: 10.1111/imm.12655

42. Zheng Y, Rudensky AY. Foxp3 in control of the regulatory T cell lineage. Nat Immunol (2007) 8(5):457-62. doi: 10.1038/ni1455

43. Du X, Liu M, Su J, Zhang P, Tang F, Ye P, et al. Uncoupling therapeutic from immunotherapy-related adverse effects for safer and effective anti-CTLA-4 antibodies in CTLA4 humanized mice. Cell Res (2018) 28(4):433-47. doi: 10.1038/s41422-018-0012-Z

44. Zeng L, Lu H, Deng H, Mu P, Li X, Wang M. Noninferiority effects on glycemic control and $\beta$-cell function improvement in newly diagnosed type 2 diabetes patients: basal insulin monotherapy versus continuous subcutaneous insulin infusion treatment. Diabetes Technol Ther (2012) 14(1):35-42. doi: 10.1089/dia.2011.0123

45. Monteiro-Sepulveda M, Touch S, Mendes-Sá C, André S, Poitou C, Allatif O, et al. Jejunal $\mathrm{T}$ cell inflammation in human obesity correlates with decreased enterocyte insulin signaling. Cell Metab (2015) 22(1):113-24. doi: 10.1016/ j.cmet.2015.05.020

46. Rhodes KA, Andrew EM, Newton DJ, Tramonti D. Carding SR. A subset of IL-10-producing $\gamma \delta \mathrm{T}$ cells protect the liver from Listeria-elicited, CD8+ T cell-mediated injury. Eur J Immunol (2008) 38(8):2274-83. doi: 10.1002/ eji.200838354

47. Guzik TJ, Skiba DS, Touyz RM, Harrison DG. The role of infiltrating immune cells in dysfunctional adipose tissue. Cardiovasc Res (2017) 113(9):1009-23. doi: $10.1093 / \mathrm{cvr} / \mathrm{cvx} 108$

48. Simar D, Versteyhe S, Donkin I, Liu J, Hesson L, Nylander V, et al. DNA methylation is altered in B and NK lymphocytes in obese and type 2 diabetic human. Metabolism (2014) 63(9):1188-97. doi: 10.1016/j.metabol.2014.05.014

49. Carvelli J, Piperoglou C, Bourenne J, Farnarier C, Banzet N, Demerlé C, et al. Imbalance of circulating innate lymphoid cell subpopulations in patients with septic shock. Front Immunol (2019) 10:2179. doi: 10.3389/fimmu.2019.02179

50. Kim Y, Bayona PW, Kim M, Chang J, Hong S, Park Y, et al. Macrophage lamin $\mathrm{A} / \mathrm{C}$ regulates inflammation and the development of obesity-induced insulin resistance. Front Immunol (2018) 9:696. doi: 10.3389/fimmu.2018.00696

51. Kawarabayashi R, Motoyama K, Nakamura M, Yamazaki Y, Morioka T, Mori K, et al. The association between monocyte surface CD163 and insulin resistance in patients with type 2 diabetes. J Diabetes Res (2017) 2017:1-9. doi: 10.1155/2017/ 6549242

52. Wu D, Molofsky AB, Liang H-E, Ricardo-Gonzalez RR, Jouihan HA, Bando $\mathrm{JK}$, et al. Eosinophils sustain adipose alternatively activated macrophages associated with glucose homeostasis. Science (2011) 332(6026):243-7. doi: $10.1126 /$ science. 1201475 
53. Mahallawi WH, Khabour OF, Zhang Q, Makhdoum HM, Suliman BA. MERS-CoV infection in humans is associated with a pro-inflammatory Th1 and Th17 cytokine profile. Cytokine (2018) 104:8-13. doi: 10.1016/j.cyto. 2018.01.025

54. Kulcsar KA, Coleman CM, Beck SE, Frieman MB. Comorbid diabetes results in immune dysregulation and enhanced disease severity following MERS-CoV infection. JCI Insight (2019) 4(20):1-18. doi: 10.1172/jci. insight. 131774

55. Qin C, Zhou L, Hu Z, Zhang S, Yang S, Tao Y, et al. Dysregulation of immune response in patients with COVID-19 in Wuhan, China. China (February 17 2020) (2020) 15:762-8. doi: 10.1093/cid/ciaa248

56. Liu Y, Zhang C, Huang F, Yang Y, Wang F, Yuan J, et al. Elevated plasma level of selective cytokines in COVID-19 patients reflect viral load and lung injury. Natl Sci Rev (2020) 109:1-8. doi: 10.1093/nsr/nwaa037

57. Pantanetti P, Cangelosi G, Ambrosio G. Potential role of incretins in diabetes and COVID-19 infection: a hypothesis worth exploring. Internal Emergency Med (2020) 15:1-4. doi: 10.1007/s11739-020-02389-x

58. Verma A, Shan Z, Lei B, Yuan L, Liu X, Nakagawa T, et al. ACE2 and Ang-(17) confer protection against development of diabetic retinopathy. Mol Ther (2012) 20(1):28-36. doi: 10.1038/mt.2011.155

59. Seferović PM, Coats AJ, Ponikowski P, Filippatos G, Huelsmann M, Jhund PS, et al. European Society of Cardiology/Heart Failure Association position paper on the role and safety of new glucose-lowering drugs in patients with heart failure. Eur J Heart Failure (2020) 22(2):196-213. doi: 10.1002/ejhf.1673

60. Shao S, Xu Q, Yu X, Pan R, Chen Y. Dipeptidyl peptidase 4 inhibitors and their potential immune modulatory functions. Pharmacol Ther (2020) 209:107503. doi: 10.1016/j.pharmthera.2020.107503
61. Kawasaki T, Chen W, Htwe YM, Tatsumi K, Dudek SM. DPP4 inhibition by sitagliptin attenuates LPS-induced lung injury in mice. Am J PhysiolLung Cell Mol Physiol (2018) 315(5):L834-L45. doi: 10.1152/ajplung. 00031.2018

62. Satoh-Asahara N, Sasaki Y, Wada H, Tochiya M, Iguchi A, Nakagawachi R, et al. A dipeptidyl peptidase- 4 inhibitor, sitagliptin, exerts anti-inflammatory effects in type 2 diabetic patients. Metabolism (2013) 62(3):347-51. doi: 10.1016/j.metabol.2012.09.004

63. Smelcerovic A, Kocic G, Gajic M, Tomovic K, Djordjevic V, StankovicDjordjevic D, et al. DPP-4 Inhibitors in the Prevention/Treatment of Pulmonary Fibrosis, Heart and Kidney Injury Caused by COVID-19-A Therapeutic Approach of Choice in Type 2 Diabetic Patients? Front Pharmacol (2020) 11:1185. doi: 10.3389/fphar.2020.01185

64. Solerte SB, Di Sabatino A, Galli M, Fiorina P. Dipeptidyl peptidase-4 (DPP4) inhibition in COVID-19. Acta Diabetol (2020) 57(7):779-83. doi: 10.1007/ s00592-020-01539-z

Conflict of Interest: The authors declare that the research was conducted in the absence of any commercial or financial relationships that could be construed as a potential conflict of interest.

Copyright $\odot 2021$ Rahmani-Kukia and Abbasi. This is an open-access article distributed under the terms of the Creative Commons Attribution License (CC BY). The use, distribution or reproduction in other forums is permitted, provided the original author(s) and the copyright owner(s) are credited and that the original publication in this journal is cited, in accordance with accepted academic practice. No use, distribution or reproduction is permitted which does not comply with these terms. 